\title{
Controlling in the System of Budgeting in an Organization
}

\author{
Nikulina S.N. \\ Kurgan State Agricultural Academy named after T.S. Maltsev \\ Lesnikovo settlement, Kurgan Oblast, Russia \\ e-mail: niksar2002@mail.ru
}

\begin{abstract}
In this paper, a coordinating function of controlling is analyzed, the area of budget controlling is established, its definition is provided, as are its types. Objectives of current budget controlling are defined. The goal and specific objectives of strategic budget controlling are presented. Budget controlling is used to coordinate the relations between different stages of budgeting subsystems when performing the tasks of budget planning, accounting, control and analysis with a purpose of ensuring organization's vitality.
\end{abstract}

Keywords - budgeting system, stages, controlling, operational and strategical budget controlling.

\section{INTRODUCTION}

The budgeting system includes several stages. A correct selection of their sequence leads to formation of documents of practical value. Execution of all the sequential stages will lead to successful budget management as a result of join operation of all the employees of an organization involved in budgeting.

At that, a question arises on coordination of budgeting subsystems; the authors think this question may be resolved with budget controlling. Before considering its nature, let us first analyze the concept of controlling as a whole.

In the modern context, activities of Russian organizations are primarily aimed at increasing the production efficiency, management improvement, increasing workforce productivity, reducing production expenses, reduction of transactional expenses, production of competitive products, improvement of financial and economic results of operations. From this point of view, there is a need to develop such a financial strategy for development of economic entities that will allow for efficient distribution and use of various resources. On its foundation, it will be possible to ensure stable market position and management based not only on the current situation, but on the foundation of budgets, analyses and forecasts (status of markets of produced goods, assessment of potential risks, etc.).

\section{RESULTS AND DISCUSSION}

Analysis of theory and practice of management shows that implementation of a financial strategy in an organization is facilitated by implementation and use of a controlling system. Currently the concept of controlling is widely used in theory and practice of business management in Russia and abroad. As a practical system, controlling has been in use in the USA since mid-1880s. D. Khan refines in [5] that "development of a theoretic concept of controlling started in Germany and other German-speaking countries in 1970s". Today, however, there is no uniform view of the nature of controlling, its interaction with other categories of management and managerial accounting. Scientific literature contains many different definitions and concepts of controlling. Russian and foreign scientists are providing managerial, coordinating, accounting and information concepts of controlling. Controlling is sometimes identified with managerial accounting, or with management, or with control.

In general, N.G. Verstnina, Iu.Ia. Eleneva, S.V. Poplitova [2] hold that the controlling includes goal setting, current gathering and processing of data for approval of managerial decisions, functions of operational control over deviation of actual indicators of activity from planned values, their assessment and analysis, as well as validating possible variants of managerial decisions. At the same time, the above mentioned authors refine that by coordinating, integrating and directing the activities of the whole organization management system to attaining the set goals, controlling performs the function of "managing the management" and is a certain synthesis of such management subsystems as planning, accounting (largely managerial one), operational control. analysis and some others.

In a modern economical dictionary it is stated that "controlling is 1) a tool of planning, accounting, analysis of situation in a company, used for decision-making on the basis of computerizing the gathering and processing of information; 2) name of a company's department in industrial enterprises in Germany and USA; 3) a system of continuous assessment of various sides of activities of a company, its business lines, managers and employees including accounting, analysis and control as an integral function".

Thus, controlling is reflected in theoretical and practical issues of management. Different definitions may be used though. In particular, according to I.V. Antonov, [1], the word controlling means one of business processes and a function in management system of an organization; a department in the economic entity's organizational structure, whose personnel consists of controllers; explicitly the process of managing economic entities in an organization that includes planning, control, accounting, analysis and managerial decision-making with feedback. Our point of view coincide with that of the above mentioned author, that these elements are brought together into a single system, as the feedback management is coordinated with the help of the controlling, a business process performed with participation from a functional department that is a facilitator of specific functions in the organization management system. 
Coordinating function of controlling is seen, for example, in coordinating target values of the organization's indicators and data from plans and budgets; determining the nomenclature of accounting information for calculation of all the indicators; coordination with other suppliers of information and data necessary for formation of budget indicators (marketing department, logistics department, etc.); determining the mechanism for getting planning (budget) information and data on the facts of economic life.

As a component of management information system, controlling is a supplier of essential information for management, which is a road map for managerial decisionmaking. Those responsible for management of the economic entity are forecasting and planning a future state of the entity, getting the data on its current state, analyzing information, which we think should include transaction costs, and use it to propose various variants to influence the entity. Thus, one may note that the controlling supports the manager in methodological, informational and institutional aspect.

Thus, controlling as a function directly related to managerial information includes also non-financial and noneconomic information. According to I.V. Antonov, controlling will be responsible for explaining the relations between dynamics of indicators in various business lines, for linking cost indicators from accounting and non-financial indicators reflecting the dynamics of financial indicators [1].

M.M. Romanova, V.A. Borodin [4] are of an opinion that controlling is more efficient in organizations that simultaneously produce and sell finished and unfinished goods, perform works and services with various level of profitability, as it is better in establishing the market conditions and degree of profitability and allows taking it into account in managerial decision-making.

When arranging the controlling, it is necessary to take into account the economic subjects of management, which are a defining factor. That is why controlling may be classified depending on the object of control (Table). This classification is systematized and expanded by the authors by such an object of management as budgeting, with a corresponding type of budget controlling. If the object of management is operational and/or strategic budgets, then it is operational and/or strategic controlling.

TABLE I. TYPES OF CONTROLLING DEPENDING ON THE OBJECT OF MANAGEMENT

\begin{tabular}{|l|l|}
\hline \multicolumn{1}{|c|}{ Object of management } & \multicolumn{1}{c|}{ Type of controlling } \\
\hline Sales & Marketing controlling \\
\hline Resources & Controlling of resource supply \\
\hline Logistics & Logistics controlling \\
\hline Monetary resources & Financial controlling \\
\hline Investment & Investment controlling \\
\hline Production & Production controlling \\
\hline Taxes & Tax controlling \\
\hline Personnel & HR controlling \\
\hline Technologies & Technological controlling \\
\hline Information technologies & IT controlling \\
\hline $\begin{array}{l}\text { Budgets (operational and } \\
\text { strategic budgets) }\end{array}$ & $\begin{array}{l}\text { Budget controlling (operational and strategic } \\
\text { budget controlling) }\end{array}$ \\
\hline
\end{tabular}

Controlling is divided into strategic and operational ones depending on the type of actualized goals. The strategic controlling is primarily oriented towards identification and tracking of future opportunities and risks of the organization in the long term, that is, search for, expansion and preservation of the development potential. T.M. Mezentsev, K.S. Saenko, A.V. Poliakov are of an opinion that the goal of the operational controlling is to create a system of management for attaining the operational goals of the economic entities, as well as making timely decision, primarily in the area of optimization of expenses and profits [3].

We are of an opinion that it is necessary to establish the area of budget controlling, as budget planning, development of budgeting model and plan-fact analysis have a significant influence over attainment of the organization's goal of sustainable development. The term budget controlling is rarely used, but it has a right to exist. Some practicing scientist, for example, V.E. Khrutskii and V.V. Gamaiunov [6] define budget controlling as a period during which operational control is performed and plan-fact analysis is conducted, a period and procedure for managerial decision-making on the basis of the results from the plan-fact analysis.

If we take into account the relations between the managerial accounting and controlling, this concept is of a wider range. Activities shall be coordinated throughout the stages of budgeting. In addition, managerial budget reports may contain on-financial indicators.

According to our definition, budget controlling is a component of controlling that allows coordinating the stages of budgeting by subsystems, actualizing certain functions and improving the efficiency of the budgeting system. Here, the leading role of the coordination function of controlling is highlighted again.

We identify the following objectives of the budget controlling:

- identification and approval of economic entities of the budget management;

- definition of critical factors and procedures for calculation of indicators that reflect them in budget planning;

- agreement and approval of key values of the indicators;

- agreement of the indicators' key values with budget data; development of a nomenclature of accounting data sufficient for calculation of indicators with its subsequent agreement with financial and managerial accounting;

- conducting plan-fact analysis; investigating the causes of deviations from key values of the indicators;

- preparation of a report on attainment of key values of the indicators; evaluation of the situation for managerial decision-making.

Performing coordination of interactions between the stages of the budgeting system as a primary function of the budget controlling assumes assessment of efficiency of the budget system, multiple choice in the management schemes of financial and non-financial information management, 
formation of of budgets and budgetary policy of the organization, risk assessment for different variants of the budget, correcting the budgets in case of force majeure, efficiency forecast for the applied budget measures.

Implementation of the function for coordination of interactions between the stages by budgeting subsystems means a constant regulation activity during the budget planning, accounting, control, analysis, in accordance with the business process technologies, sectoral standards, approved budget polity (it may be a part of the managerial accounting policy) and budgeting procedure (Figure ).

In order to provide a more accurate delimitation of functions in the system of budget controlling, we hold it is justified to separate budget assessment and budget regulation into separate subsystems, while previously they were included into budget planning, analysis and budget control. Budget regulation is a formation of the organization's budget that facilitates joint operation of business lines and their heads in order to attain planned goals. In addition, it includes generalization of lessons learned and preparation of proposals for improvement of the existing budgeting system. Budget assessment, as the budget is the plan expressed in monetary terms, a degree of its fulfillment may be used as an assessment criterion for the results of activities of business lines (centers of financial responsibility) and their managers.

Development of the budget controlling system starts with conducting the organization's diagnostics, analysis of presence, actual state and functioning of the budgeting system. At this stage, problems are identified with the purpose of stating necessary changes. Subsequently, mechanisms of controlling are developed and implemented in accordance with the identified problems and features (sectoral, technological, etc.) of the organization.

Definition of the budgetary procedure is important for the budget controlling and for the budgeting system as a whole. The budgetary procedure is a set of special rules that set up a procedure of budgeting activities in the budgeting system. The budgetary procedure is defined in a corresponding subsystem.

Thus, budget controlling allows coordinating relations through the stages of budgeting by the mentioned subsystems. It leads to an actual goal setting for the budgetary period, search of alternative ways to attain the set goals and selection of the optimal ones of them, adoption of measures aimed at reworking of budgets or regulations, rectification of deviations or goal correction.

As a whole, the result of implementing the budget controlling will be a system that allows forecasting the results of budgetary activities; forming budgets with the purpose of increasing the efficiency in resource use; timely acquisition of accurate information necessary for budget-related decisionmaking; efficiently using budget planning and budget optimization schemes; operational performance of budget analysis; correcting budgets where necessary; controlling the efficiency of the budgeting system. All this facilitates improving the efficiency of activities of the economic entity.

We hold that operational budget controlling allows coordinating the stages of budgeting by subsystems, actualizing certain functions and improving the efficiency of the operational budgeting.

Budget controlling is understood as coordination of relations between different stages of budgeting subsystems when performing the tasks of budget planning, accounting, control and analysis with a purpose of ensuring organization's vitality in the long term.

The main objective of the strategic budget controlling may be defined as provision of competitiveness of the organization and development of its potential in the long term on the basis of management decisions taken with the help of the budgeting system. The main purpose of the strategic budget controlling is coordination of the functions in the budgeting system during attainment of strategic goals. The nature of the coordination lies in forming and using budgetary information space in performance of management functions during strategic managerial decision-making.

Within the framework of strategic budget controlling, the stages of budgeting are coordinated while resolving the following specific tasks:

- reflection of strategic goals (directions) in long-term budgets;

- determining a budget period in strategic budgets;

- ensuring integration of long-term strategic goals and operational objectives in budget planning;

- strengthened analysis of external factors;

- implementation of permanent budget control of strategic indicators;

- reflection of strategic accounting information;

- analysis of strategic budgets, managerial budgetary reporting that contains strategic indicators,

- long-term management of economic and financial activities of the organization.

Thus, application of the strategic budget controlling will allow the organization to determine critical external and internal factors forming a foundation of strategic budget planning; developing alternative strategies; define controlled budgetary indicators in accordance with the strategic goals; analyze economic activity indicators with a special attention paid to innovations and investment [7]; correct the strategic goals and measures where necessary.

\section{CONCLUSION}

Thus, using a relation between the systemic and the institutional approach and a reflection of the budgeting procedure as a sequence of stages shows that the subsystems interpenetrate and interact in the budgeting system, while their integrating means ins the process of communications. Only performance of all the stages by subsystems will show a result of joint activities of the organization's personnel and will lead to efficient budgeting. Coordination of the budgeting stages is proposed by means of budget controlling. The authors defined 
its nature, objectives and formative procedure with the purpose of subsequent scientific development. Implementation of the budget controlling allows making provisions for the results of budgeting activity, forming budgets, efficiently using budget planning and budget optimization schemes, timely acquisition of actual information for budgetary decision-making and performing budget analysis, controlling the efficiency of the budgeting system. The specific features of the strategic budget planning as defined by the author, allow the organization to determine critical factors forming a foundation of the budget planning, develop alternative strategies, form budget indicators in accordance with the strategic goals, analyze economic efficiency indicators, correct strategic goals.

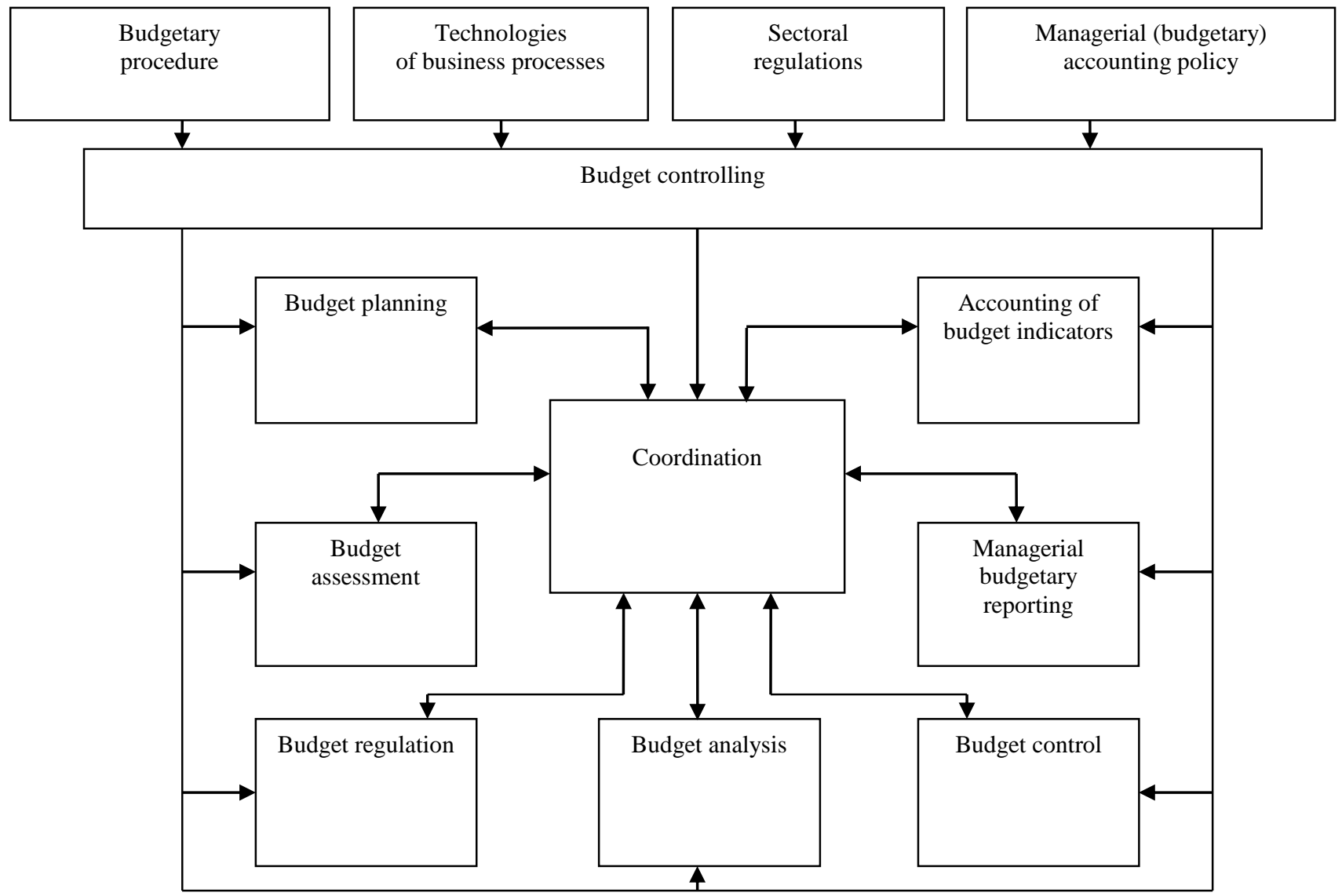

Fig. 1. A scheme of operation of budget controlling in coordination of stages by budgeting subsystems (author's interpretation)

\section{References}

[1] I.V. Antonov, "Concept of controlling and practice of its application", IFSR and ISA in a lend. institut., no. 3, 2008.

[2] N.G. Verstina, Iu.Y. Eleneva, S.V. Poplitova, "Budgeting in the operation of a construction enterprise: problems and their practical solutions", Econ. of Construct., no. 3, pp. 28-38, 2005.

[3] T.M. Mezentseva, K.S. Saenko, A.V. Poliakov, "Financial strategy of enterprise development: budgeting and transfer prices", Audit Gazette, no. $1,2001$.
[4] M.M. Romanova, V.A. Borodin, "Application of new management methods in enterprises", Econ. Anal.: Theory and Pract., no. 19, 2007.

[5] D. Khan, Planning and control: the concept of controlling. Translated from German, ed. and preface by A.A. Turchak, L.G. Golovach, M.L. Lukashevich. Moscow: Finansy i Statistika, 1997, 800 p.

[6] V.E. Khrutskii, V.V. Gamaiunov, Intracompany budgeting: Desk companion for installation of financial planning, 2rd ed., updated and revised. Moscow: Finansy i Statistika, 2008, 464 p.

[7] S.N. Nikulina, A.A. Butyugina, E.E. Gorbunova, "Investment activity in conditions of automation use of budgeting system", IOP Conf. Ser.: Earth and Environmental Sci., vol. 341, 2019. DOI: 10.1088/1755$1315 / 341 / 1 / 012217$ 